\title{
Characterization and Technical Evaluation of A Novel Concrete from Recycle Concrete as A Coarse Aggregate
}

\author{
Wadhah M. Tawfeeq ${ }^{1}$, Fatema Ahmed Al-Housni ${ }^{2}$, Najla Abdulrahman Al-Qasmi ${ }^{2}$, Sabha Ali Al.Gafri ${ }^{2}$, \\ Sheikha Mohammed Al.Jahwari ${ }^{2}$ \\ Assistant Professor, Faculty of Engineering, Sohar University, Sohar, Oman ${ }^{1}$ \\ Under Graduate Student of Engineering, Sohar University, Sohar, Oman ${ }^{2}$
}

\begin{abstract}
Crushed concrete is a construction and demolition waste that causes environmental pollution. The reused of crushed concrete as aggregate in new concrete mix has been common practice in many countries. As a result it is a necessary to determine the behavior of crushed aggregate used in concrete production. This project reports the results of an experimental study on the properties of crushed aggregate concrete compared to natural aggregate concrete and investigating the effect of two different old concrete properties (M1 \& M2) on producing new concrete.It was found that, average dry bulk specific gravity of natural coarse aggregate was $2.73 \%$, average of bulk Specific gravity was 2.75 and water absorption was $0.449 \%$. On the other hand, average dry bulk specific gravity of crushed coarse aggregate was 2.46 for M1 and 2.4 for M2. The average bulk specific gravity of crushed aggregate was 2.6 for M1 and 2.54 for M2. Crushed coarse aggregate water absorption was $5.8 \%$ for M1 and $6.2 \%$ for M2. For water content the average percentage was $2.24 \%$ for crushed aggregate for M1 and $2.78 \%$ for M2. However it was $0.13 \%$ for natural aggregate. The slump results show that slump was higher at $100 \%$ and lower at $0 \%$ replaced crushed aggregate.The effects of replaced aggregate percent on compressive strength shows that the compressive strength decrease with increasing the volume of crushed aggregate that has been used in the mix.
\end{abstract}

Keywords: Technical Evaluation, Novel Concrete, Compressive Strength, Slump, Physical Properties, Trial Mix, Recycled, Aggregate.

\section{INTRODUCTION}

As the needs of having accessible building materials, civil benefits of using recycling. One ex-ample of those is using engineers had come up with a new idea of recycling. The it for transportation and road building. The Washington definition of recycling is the process of collecting and State Department of Transportation (WSDOT) is reprocessing materials that would typically be considered considering using recycled concrete aggregate (RCA) as a waste [1]. Recycled aggregate (RA) is aggregate resulting substitute for some of the virgin aggregate used to produce from the processing of inorganic material previously used hydraulic cement concrete pavement (PCCP). The source in construction [2]. The experiments on recycling started a of this aggregate would be existing PCCP that has reached long time ago and a lot of investigation have been done in the end of its structural life and must be replaced [4]. In this field. To some extent, the investigation on recycled addition, recycling materials that would otherwise end up waste concrete was initiated by Glushge in Russia 1946. In in a landfill is good for the environment. This is the following years, a large amount of experimental works particularly true when you are dealing with bulk materials have been carried out worldwide to investigate the that take away precious space for real garbage [5]. recycling of waste concrete [2].

Many countries started to use recycling in their buildings or roads. The technology of concrete recycling is well established in the U.S. Recycling of Portland cement concrete, as well as asphaltic concrete, has been shown to be a cost-effective alternative for new road, street, and highway construction [3]. The Environmental Council of Concrete Organizations also pointed out that it is generally accepted that when natural sand is used, up to $30 \%$ of natural crushed aggregate can be replaced with coarse recycled aggregate without significantly affecting any of the mechanical properties of the concrete. There are many

A series of experiments using recycled aggregate of various compositions from building rubble was conducted. The test results show that the building rubble could be transformed into useful recycled aggregate through proper processing. Using unwashed recycled aggregate in concrete will affect its strength. The effect will be more obvious at lower water/cement ratios. When the recycled aggregate was washed, these negative effects were greatly improved. This is especially true for the flexural strength of the recycled concrete. The recycled coarse aggregate is the weakest phase at a low water/cement ratio. This effect will dominate the strength of recycled concrete. This 
Vol. 4, Issue 1, January 2017

mechanism does not occur in recycled mortar. The quantity of recycled fine aggregate will govern the mortar strength. Although using brick and tile in concrete will affect its mechanical properties, the effect are limited [6].

Dunster (2007) [7] described the use of both natural stone waste and production waste as coarse aggregates in concrete landscaping products. Many of these concrete products routinely include industrial by products and recycled/secondary aggregates. Example include mainly recycled concrete aggregates (from crushed production waste), furnace bottom ash (FBA), ground granulated blast furnace slag (GGBS), pulverized fuel ash (PFA). Increasingly, manufacturers of landscaping products crush this material into recycled concrete aggregate (RCA) at the manufacturing site and recycle into new production as a partial replacement for primary aggregates.

Mashitah, M.D. et al (2008) [8] showed that as the numbers of landfills are diminishing, there is dire need to recycle used building material. In the matter of industrial waste ceramic, compressive strength of produced concrete is unchanged when the waste was used to partially replace conventional crushed stone course aggregate. During construction activities, a lot of homogenous tiles are used for heavy duty usage, as they are much harder, durable and highly resistant to biological, chemical and physical degradation forces. However, development of tiles-based materials are less reported and let alone be exploited, though it could provide an enor-mous economic and environmental benefit to the society in general. This work is aimed at evaluating the possibility of reusing ceramic tiles from construction sites as aggregate for production of concrete block.

Wadhah M Tawfeeq et al, (2016)[9] investigated the possible use of crushed pavement blocks as coarse aggregate for the production of new concrete. The concrete specimens were prepared by $100 \%$ natural coarse aggregate; which would then be replaced by crushed pavement blocks at various percentages (50 and 100\%). The mechanical and physical properties of crushed pavement block aggregates such as specific gravity, clay percent, grading, water content and water absorption were tested. Experimental results indicated that absorption of coarse crushed pavement blocks aggregate were about $221 \%$ higher than that of natural aggregate. The compressive strength of 28 days by using crushed pavement blocks aggregate showed an increment of nearly $8 \%$ when it fully re-placed the natural aggregate in concrete mixes.

Wadhah M Tawfeeq et al, (2016)[10] conducted an experimental investigation to study the flexural behaviour of concrete beams with stone slurry as a fine aggregate. General properties of aggregate were studied such as specific gravity, water absorption and water content. Six beams casted with different stone slurry replacement contents varying from $0 \%-50 \%$ by. All the beams were simply supported and subjected to one concentrated loads at mid-span of the beam, by using $600 \mathrm{kN}$ flexural and transverse frame. It has found that the plain cement concrete specimen has shown a typical crack propagation pattern which leaded into splitting of beam. But due to replacement of 5\% stone slurry, cracks gets ceased which result into ductile behaviour. The optimum percent of stone slurry to be used was found to be $5 \%$. Also the compressive strength of concrete cubes is increased slightly by the replacement of 5\% stone slurry. The load carrying capacity were com-pared with theoretical values calculated using BS8110 (Design Manual).

Wadhah M Tawfeeq et al, (2016)[11] studied the possible use of crushed Concrete Hollow Blocks as coarse aggregate to produce a new concrete by using construction and demolition waste as raw material to give positive effect on the economy. The compressive strength of concrete at $7 \& 28$ days of age of concrete mix have been determined using natural coarse aggregate. The replacement of the coarse aggregate by crushed Concrete Hollow Blocks was at three different percentages $(0 \%, 50$ $\%$, and $100 \%$ ). The mechanical and physical properties of aggregate were investigated such as specific gravity, water absorption, water content, sieve analysis and clay percent. Wadhah M Tawfeeq et al, (2016)[12] investigated the effects of using the crushed tiles (CT) as a coarse aggregate in the concrete mix. The CT is an industrial waste material, and then reuses it in the construction fields will reduce the concrete costs and reduce the environmental pollution. The general properties, such as the specific gravity, water absorption and water content of the natural crushed aggregate and the CT aggregate were tested and compared with natural aggregate. Three different replacement percentages of CT aggregates $(0 \%$, $50 \%$ and $100 \%$ ) were used in the concrete mix, in each replacement percentage; W/C and G/S were changed as a parametric study to investigate their effects on slump and compressive strength. In general, the results confirm that increasing the $\mathrm{W} / \mathrm{C}$ will cause to increase the workability and decrease the compressive strength of the concrete mix that with CT aggregate. For example, the compressive strength of concrete mix for $100 \%$ replacement of crushed tiles was $28 \mathrm{MPa}$ with $\mathrm{W} / \mathrm{C}=0.55$ and $\mathrm{G} / \mathrm{S}=1.1$, in comparison with control mix $(0 \%$ of CT) was $38.8 \mathrm{MPa}$; showed $27.83 \%$ decreasing. While the slump of fresh concrete showed $37.50 \%$ increasing.

In summary, recycling concrete helps in saving natural building materials in addition to reducing the pollution that those crushed concrete can do to the earth if ended up in landfills. Crushed concrete can be found in demolition of buildings, bridges and roads. Instead of being thrown in garbage, those materials are precious and can be helpful. They can be used in making new concrete and paving roads. In addition, the quality of recycled building materials is almost as good as the natural materials as it affects limitedly on the mechanical proprieties of concrete.

\section{METHODOLOGY}

In this study, two types of aggregates have been used, natural aggregate and crushed aggregate with $(0 \%, 25 \%$, 
Vol. 4, Issue 1, January 2017

$50 \%, 75 \%$ and $100 \%$ ) replacement. This crushed aggregate produced from two different concrete trial mixes M1 is $1: 2: 4 / 0.5$ and M2 is $1: 2: 3 / 0.45$. Before mixing, many tests on natural and crushed materials were done to investigate and compare their properties. Sieve analysis, water content, water absorption, specific gravity, and clay percent tests. To investigate the effect of crushed aggregate replacement percentage on the new concrete, a concrete trial mix has been adopted. The cement quantity for all mixes was $400 \mathrm{~kg}$. The different replacement ratios were used for coarse aggregate $(25 \%, 50 \% \& 100 \%$ replacement). The (gravel/sand) ratio was used (1.1). The (cement/water) ratio was used (0.5). The water was adjusted to keep the slump between 100-180 mm. Before mixing, the characterizations of aggregates such as the grading, water absorption, water content, abrasion and clay percent tests were measured. The bench marking trial mix was $400: 835.2: 904.8 / 0.6$ for one meter cube of concrete. The expected 28 days compressive strength is more than $35 \mathrm{MPa}$ and the workability (slump) between $100-180 \mathrm{~mm}$.

\section{III.EXPERIMENTAL MATERIALS}

Natural sand from local crusher in Salan was used. The grading of of the fine aggregate conforms to the British specification BS 882: $1992^{\text {[9] }}$. Also average of three samples was taken to evaluate the bulk specific gravity, water absorption, water content and clay percentage, the values were 2.66, 3.92\%, $3.55 \%$ and $2.73 \%$ respectively.Crushed gravel of maximum aggregate size $20 \mathrm{~mm}$ from Saa'a region was used. The average of three samples was taken to evaluate the bulk specific gravity, water absorption and water content, the values were $2.75,0.449 \%$ and $0.13 \%$ respectively. Crushed aggregate produced in laboratory and it was graded in the laboratory. For M1, the average of three samples was taken to evaluate the bulk specific gravity, water absorption and water content, the values were 2.6, 5.8\% and $2.24 \%$ respectively. For M2, the average of three samples was taken to evaluate the bulk specific gravity, water absorption and water content, the values were 2.54 , $6.2 \%$ and $2.78 \%$ respectively.The grading of this aggregate conforms to the British Specification BS $882: 1992^{[13]}$. The cement used in this study is Fujairah cement industries O.P.C. according to British Standard Specification BS EN 197-1:2000 $0^{[14]}$. Potable water was used in concrete trial mixes and in curing.

\section{IV.RESULTS AND DISCUSSIONS}

The replacement percent of recycle aggregate were $0 \%$, $25 \%, 50 \%, 75 \%$ and $100 \%$ in separate mixture. For each concrete mixes the slump and 28 days compressive strength have been calculated.

The slump was measured directly at the end of each mixes casting which represent the workability of concrete and the strength was measured after $7 \& 28$ days from casting. The results are shown in the figures below.

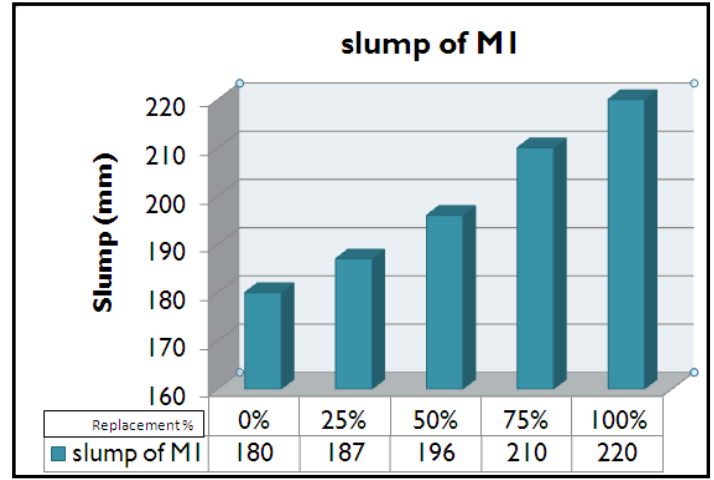

Fig. 1 Slump Test of M1

As shown in Fig. 1 the slump of concrete mix was affected by the moisture condition of aggregate. However, the slump of crushed concrete increased with increase the volume percent of recycled crushed concrete aggregate. As clearly visible from the figure the slump for $100 \%$ concrete crushed is the highest than $0 \%$ by $40 \%$. This is mainly due to surface shape, size difference of replacement of crushed concrete.

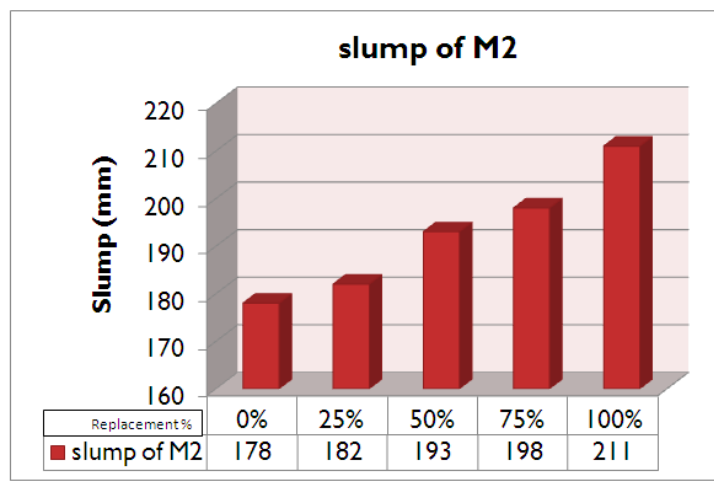

Fig. 2 Slump Test of M2

With increase the volume percent of recycled crushed concrete aggregate the slump of crushed concrete slightly increased. As shown in Fig. 2 the slump for $100 \%$ concrete crushed is the highest than $0 \%$ by $21 \%$.

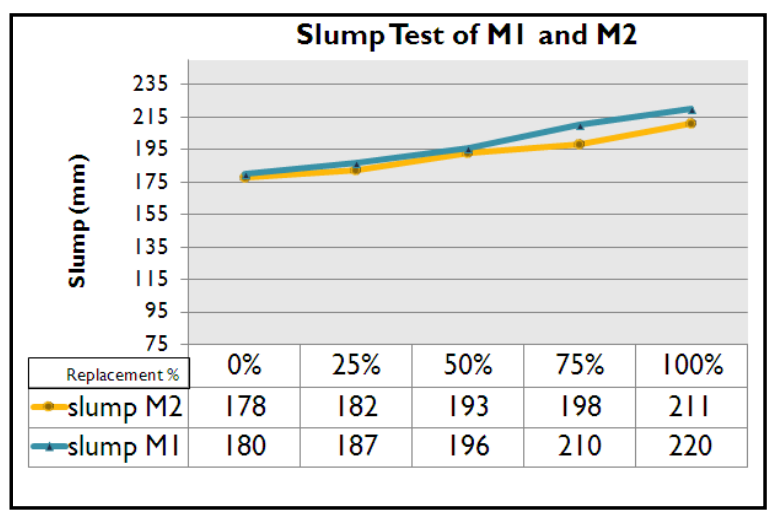

Fig. 3 Slump Tests of M1 and M2

Fig. 3 shows that slump was higher at $100 \% \mathrm{CC}$ and it was lower at $0 \% \mathrm{CC}$ for both. The difference in slump between $\mathrm{M} 1$ and M2 at maximum slump is about $10 \mathrm{~mm}$ and at 
Vol. 4, Issue 1, January 2017

minimum is $8 \mathrm{~mm}$ which shows that two graph have approximately the same trend because of the similarly of replacement concrete aggregate volume and properties.

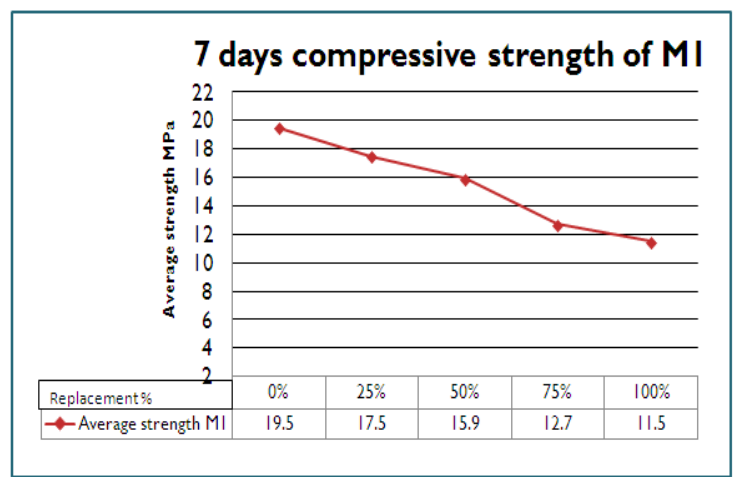

Fig. 4 days Compressive Strength M1

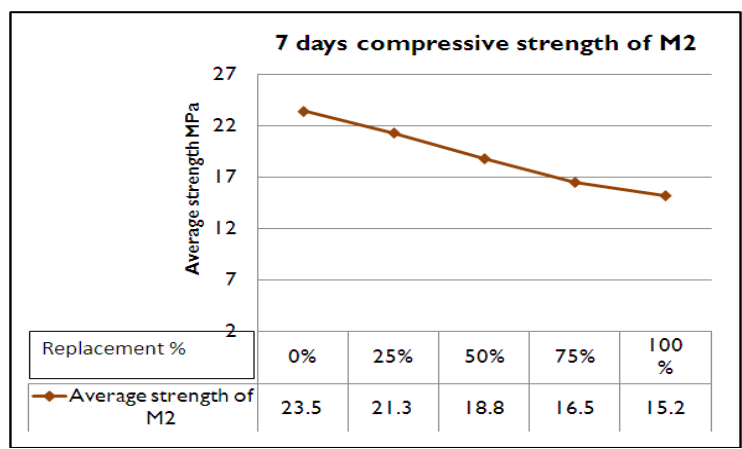

Fig. 5 days Compressive Strength M2

Fig. 4 \& Fig. 5 represent decreasing in 7 days compressive strength with increase the replacement of concrete crushed aggregate. The compressive strength is the maximum when the replacement was $0 \%$ and minimum when it was $100 \%$. In the first figure the different in strength between the natural aggregate $0 \%$ and full replacement $100 \%$ is about $8 \mathrm{MPa}$ and the second figure is about $8.3 \mathrm{MPa}$.

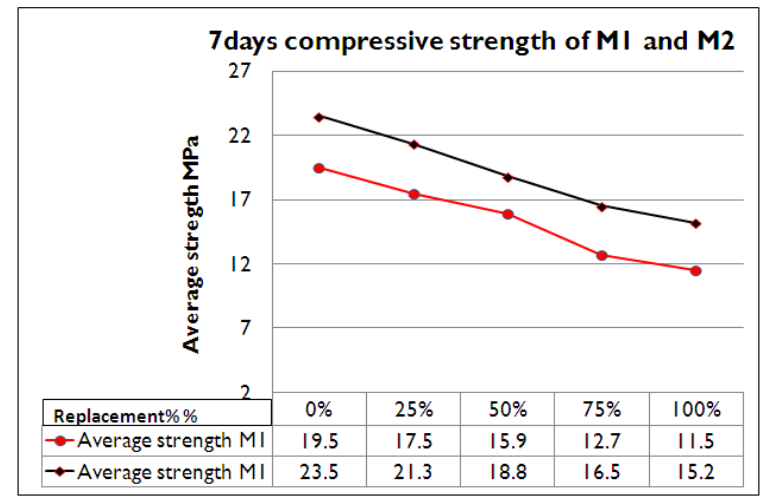

Fig. 6 7days compressive strength M1 and M2

Fig. 6 shows that the two different mixes having the same trend, they go down as increasing the replacement of concrete crushed aggregate. The differences in compressive strength between each percent of replacement are not big. At $100 \%$ the difference is $4 \mathrm{MPa}$ and at $0 \%$ is 3.7 MPa.

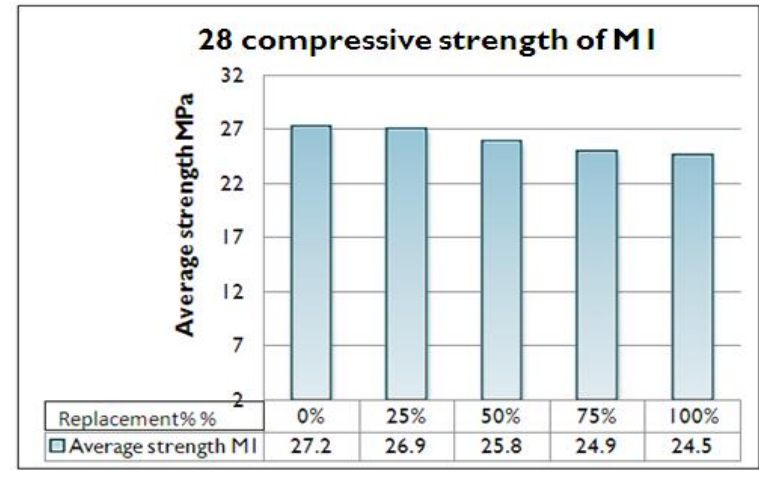

Fig 7. 28 days compressive strength M1

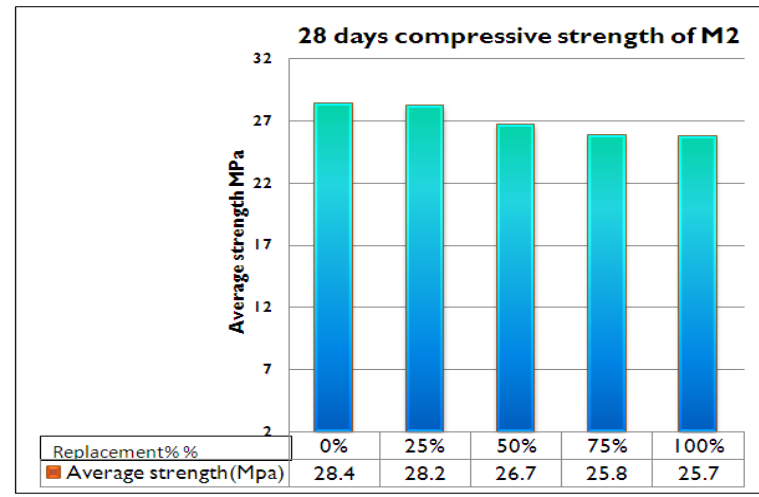

Fig 8. 28 days compressive strength M2

28 days compressive strength results are shown in the Fig. 7 \& Fig. 8. The increase in the percent of replacement caused decreased in the compressive strength of about 2.7 MPa for M1 and M2. The compressive strength is the maximum when the replacement was $0 \%$ and minimum when it was $100 \%$.

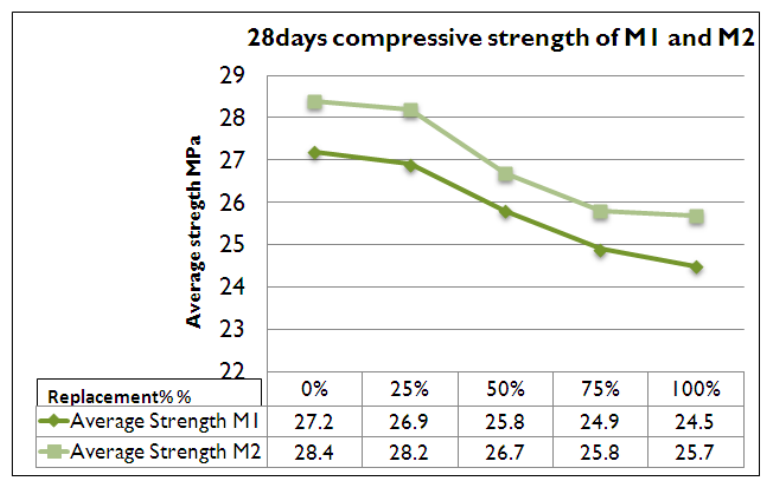

Fig 9. 28days compressive strength between M1and M2

Fig. 9 shows the relationship for all percent of replacement added the compressive strength was decreased. The highest compressive strength between two mixes is 28.4 $\mathrm{MPa}$ at $0 \%$ at $\mathrm{M} 2$ and the lowest is $24.5 \mathrm{MPa}$ at $100 \%$ at M1.

The twenty eight days results did not change from the seven days results except that the compressive strength increase but the trend is same as before. The compressive strength can be significantly effective by the replacement percentage of concrete crushed and curing condition. 
Vol. 4, Issue 1, January 2017

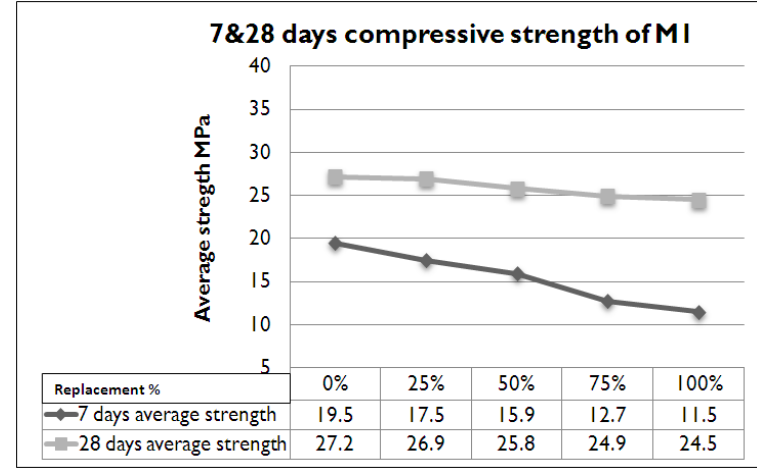

Fig. 107 and 28 days compressive strength of M1

As it is cleared the compressive strength of concrete was higher at age of 28 days by as much as approximately $13 \%$ at 7 days in full replacement and lower was 7.7 at $0 \%$, as shown in Fig. 10.

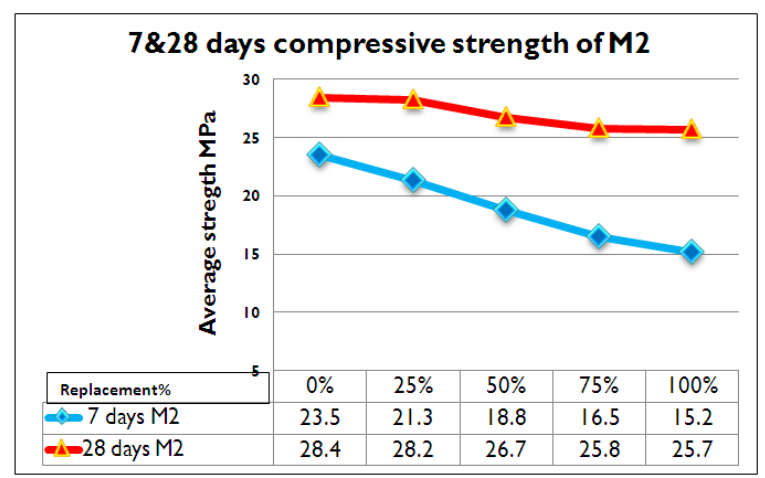

Fig. 11 7and 28 days compressive strength of M2

The percent difference is almost similar for twenty eight days compressive strength comparing with seven days compressive strength. The highest strength was for the natural aggregate $0 \%$. The compressive strength was about $10.5 \mathrm{MPa}$ difference between 7 and 28 days at $100 \%$ replaced crushed concrete, as shown in Fig. 11.

\section{CONCLUSION}

1. Sieve Analysis Test of Fine and Coarse Aggregate (Natural and Crushed Concrete).

As result of this test, the percentage passing of all sieves is within the range of nominal size graded aggregate for fine and coarse aggregate

2. Specific Gravity and Water Absorption Test of Fine and Coarse Aggregate (Natural and Crushed Concrete).

As a result of specific gravity test we got the following results, the average specific gravity of fine aggregate was $2.66 \%$ which done by gas jar test and water absorption was $3.87 \%$.The average dry bulk specific gravity of natural coarse aggregate was $2.73 \%$, average of bulk Specific gravity was 2.75 and water absorption was $0.449 \%$. On other hand, the average dry bulk specific gravity of crushed coarse aggregate was $2.46 \%$ for M1 and $2.4 \%$ for M2. The average bulk specific gravity of crushed coarse aggregate was $2.6 \%$ for M1 and $2.54 \%$ for
M2. Crushed coarse aggregate water absorption was $5.8 \%$ for $\mathrm{M} 1$ and $6.2 \%$ for $\mathrm{M} 2$.

3. Water Content (Moisture Content) Test.

The average percentage of water content of sand was $3.52 \% .0 .13 \%$ was the average percentage of water content of natural aggregate. However it was $2.24 \%$ of crushed aggregate for M1 and $2.78 \%$ for M2.

4. Clay Percent Test.

As a result of this test the average of clay percent was $2.73 \%$ so it is accepted.

5. Slump.

The increasing of percent of replaced aggregate cause increase in slump value. The slump was higher at $100 \%$ and lower at $0 \%$. From the results we found that, the slump was higher at M1 and lower at M2. This is due to water absorption ability of M2 was higher.

6. Compressive strength.

As the volume of crushed coarse aggregate in the mix increased $(0 \%, 25 \%, 50 \%, 75 \%$ and $100 \%)$, the compressive strength decreased. When we use full natural coarse aggregate the compressive strength was 43.6 $\mathrm{N} / \mathrm{mm} 2$ while, it was $28.4 \mathrm{~N} / \mathrm{mm} 2$ when full crushed aggregate was used. It decreased by $34.86 \%$.

\section{REFERENCES}

[1] Construction \& Demolition Waste. (2016, 8 Jun). Retrieved from http://www.epd.gov.hk/ epd/misc/cdm/introduction.htm

[2] Mashitah, " Recycling of homogenous ceramic tiles for the production of concrete block", School of Chemical Engineering, UniversitiSains Malaysia, 14300 NibongTebal, Penang, Malaysia (2008).

[3] H.Chen, T.Yen, K.Chen, (2002) Use of building rubbles as recycled aggregates, Retrieved 30 August 2014

[4] M.ledererova, k.Grunner, (2006) Optimization of the technology for recycling concrete materials, Retrieved 10 August 2014

[5] Astec Industries, (2014) the benefits of recycling aggregate, Retriever. 23 August 2014 from http://www.factsfiguressolutions. com/post/the-benefits-of-recycling-aggregate/

[6] K. Anderson, J Uhlmeyer, M Russell, (2009) Use of Recycled Concrete: Aggregate in PCCP: Literature Search, Washington state department of transportation. Retrieved. 23 August 2014.

[7] ECCO, (1999) Recycling Concrete and Masonry, Environmental Council of Concrete Organizations, Retrieved. 23 August 2014.

[8] M.Maryo'Mahony, (1990) Recycling of materials in civil Engineering, Retrieved 10 August 2014.

[9] Wadhah M. Tawfeeq, Othman AlShareedah, and Taimoor Hossain," Properties of Concrete Mix with Crushed Pavement Blocks as Coarse Aggregate ", International Journal Of Scientific\& Engineering Research, Volume 7, Issue 7, July-(2016).

[10] Wadhah M. Tawfeeq, AsmaAlmaqbali, AshwaqAlkhawaldi, HananAlmaqbali, and Amani Alessai," Structural Performance Of Reinforced Concrete Beam With Omani Recycled Stone Slurry ", International Journal of Advance Research, Volume 4, Issue 7, July (2016).

[11] Wadhah M. Tawfeeq, Ahmed Al-Shibli, Mohammed Al-Jarwani and Othman Al-Zakwani, "Slump and Compressive Strength of Concrete Mix with Crushed Concrete Blocks as Coarse Aggregate" International Journal of Advanced Engineering and Management Research Vol. 1 Issue 7 September (2016)

[12] Wadhah M. Tawfeeq, Maryam AlSaidi, Abdullah Al-Kamzari, Mohammed Al-Shibli, and Zainab Al-Mamari, "Using Crushed Tiles as Coarse Aggregate in Concrete Mix" 3rd International Conference on Civil, Environment and Waste Management (CEWM-16) Sept. 12-14, 2016 Dubai (UAE).

[13] BS882:1992,"Aggregates from Natural Sources for Concrete"1992.

[14] BS EN 197-1:2000. (2000). Cement. Composition, specifications and conformity criteria for common cements.British Standard. 